\title{
Outcomes of 42 pregnancies in 14 women with cartilage-hair hypoplasia: a retrospective cohort study
}

Elina Holopainen ${ }^{1,2^{*}}$ (D, Svetlana Vakkilainen ${ }^{2,3,4}$ and Outi Mäkitie $2,3,4,5$

\begin{abstract}
Background: Cartilage-hair hypoplasia $(\mathrm{CHH})$ is a rare skeletal dysplasia characterized by disproportionate short stature, immunodeficiency, anemia and risk of malignancies. All these features can affect pregnancy and predispose to maternal and fetal complications. This study aimed to evaluate obstetric history and maternal and fetal outcomes in women with $\mathrm{CHH}$.
\end{abstract}

Methods: Among 47 Finnish women with $\mathrm{CHH}$, we identified 14 women with ICD codes related to pregnancies, childbirth and puerperium in the National Hospital Discharge Registry and obtained detailed data on gynecologic and obstetric history with a questionnaire. Offspring birth length and weight were collected and compared with population-based normal values.

Results: There were altogether 42 pregnancies in 14 women (median height $124 \mathrm{~cm}$, range 105-139 cm; $4^{\prime} 1^{\prime \prime}$, range $\left.3^{\prime} 5^{\prime \prime}-4^{\prime} 7^{\prime \prime}\right)$. Twenty-six pregnancies (62\%), including one twin pregnancy, led to a delivery. Miscarriages, induced abortions and ectopic pregnancies complicated 9, 5, and 2 pregnancies, respectively. Severe pregnancy-related complications were rare. All women with $\mathrm{CHH}$ delivered by cesarean section, mostly due to evident cephalo-pelvic disproportion, and in 25/26 cases at full-term. In the majority, the birth length (median $48 \mathrm{~cm}$, range $45.5-50 \mathrm{~cm} ; 1^{\prime} 7^{\prime \prime}$, range $\left.1^{\prime} 6^{\prime \prime}-1^{\prime} 8^{\prime \prime}\right)$ and weight (3010 $\mathrm{g}$, range $2100-3320 \mathrm{~g} ; 6.6 \mathrm{lb}$, range $4.6-7.3 \mathrm{lb}$ ) of the offspring in full-term singleton pregnancies was normal.

Conclusions: Despite $\mathrm{CHH}$ mothers' significant short stature and other potential $\mathrm{CHH}$-related effects on pregnancy outcome, most pregnancies lead to a term cesarean section delivery. Since fetal growth was generally unaffected, cephalo-pelvic disproportion was evident and planned cesarean section should be contemplated in term pregnancies.

Keywords: Pregnancy, Cartilage-hair hypoplasia, Obstetric, Cesarean section, Miscarriage

\section{Background}

Bone dysplasia, small maternal height and disproportion can all affect fertility and natural course of pregnancy, and may predispose to pregnancy and obstetric

\footnotetext{
${ }^{*}$ Correspondence: elina.holopainen@hus.fi

${ }^{1}$ Department of Reproductive Medicine, Obstetrics and Gynecology,

Helsinki University Hospital and University of Helsinki, P.O. Box 14000029 , Helsinki, Finland

Full list of author information is available at the end of the article
}

complications affecting perinatal outcomes. Women with short stature may suffer from respiratory distress during pregnancy and experience more cephalo-pelvic disproportion (CPD) leading to high rate of cesarean deliveries (CS) $[1,2]$.

Some studies have previously been performed on maternal and fetal outcome in different bone dysplasias. Pregnancies in patients with osteogenesis imperfecta can be complicated with antepartum hemorrhage, placenta abruption, intrauterine growth restriction (IUGR) original author(s) and the source, provide a link to the Creative Commons licence, and indicate if changes were made. The images or other third party material in this article are included in the article's Creative Commons licence, unless indicated otherwise in a credit line to the material. If material is not included in the article's Creative Commons licence and your intended use is not permitted by statutory regulation or exceeds the permitted use, you will need to obtain permission directly from the copyright holder. To view a copy of this licence, visit http://creativecommons.org/licenses/by/4.0/. The Creative Commons Public Domain Dedication waiver (http://creativeco mmons.org/publicdomain/zero/1.0/) applies to the data made available in this article, unless otherwise stated in a credit line to the data. 
and the birth of small-for-gestational-age infants [3]. Pregnancy-related complications in women with achondroplasia are uncommon, the most serious complications being worsening of spinal claudication symptoms and respiratory failure. Most women with achondroplasia have term pregnancies, but planned CS is required because of CPD [4]. However, most obstetric reports in patients with short stature due to skeletal dysplasia are case reports and have mainly focused on anesthetic planning and performance of cesarean delivery $[5,6]$.

Cartilage-hair hypoplasia $(\mathrm{CHH})$ is a rare autosomal recessive disorder with an incidence of 1: 23,000 live births in Finland [7]. It is characterized by short stature, hypoplastic hair, combined immunodeficiency and increased risk for malignancies, especially lymphoma. $\mathrm{CHH}$ is caused by variants in the $R M R P$ gene, encoding the RNA subunit of the mitochondrial RNA processing endonuclease, which is involved in cell cycle regulation [8]. $\mathrm{CHH}$ is a disease with significant variability in phenotypic presentation [9]. Women with $\mathrm{CHH}$ have adult height in the range of $110-140 \mathrm{~cm}\left(3^{\prime} 7^{\prime \prime}-4^{\prime} 7^{\prime \prime}\right)$, median height being $122.5 \mathrm{~cm}\left(4^{\prime} 0^{\prime \prime}\right)$ [10].

Disproportionate short stature and immunodeficiency are among the most prominent features of $\mathrm{CHH}$ and can adversely influence female patients' reproductive health. Immunodeficiency can predispose pregnant women to infections during naturally immunocompromised state in pregnancy. In addition to maternal complications, short stature might affect fetal growth and predispose to preterm deliveries. Despite the growing knowledge of disease mechanism, many clinical aspects of $\mathrm{CHH}$ remain uncharacterized. Only limited data are available regarding puberty, reproduction, and gynecologic health in patients with $\mathrm{CHH}$ [11-13]. The obstetrical literature in $\mathrm{CHH}$ is limited to case reports $[14,15]$.

The knowledge gaps in reproductive and obstetric outcomes are a significant source of concern for patients and families affected by $\mathrm{CHH}$. Lack of knowledge may affect $\mathrm{CHH}$ patients' family planning. The possibility of obstetric complications can lead medical personnel to discourage the patient from becoming pregnant.

The purpose of this study was to evaluate the incidence and course of pregnancies and maternal and perinatal outcomes in the Finnish cohort of women with $\mathrm{CHH}$.

\section{Patients and methods}

\section{Patients}

Patients were identified from the Finnish Skeletal Dysplasia Registry which includes $>110$ living patients with genetically confirmed $\mathrm{CHH}$; 56 of them were women aged over 18 years. Altogether 47 of these women were participants in our ongoing research program on $\mathrm{CHH}$. Their ICD-10 codes related to pregnancies, childbirth and puerperium $\left(\mathrm{O}^{*}\right.$-O99*) were searched from the National Hospital Discharge Registry (HILMO). Of the 47 women with $\mathrm{CHH}, 19$ had pregnancy or deliveryrelated diagnoses in the Registry, involving a total of 57 pregnancies. These 19 women were subsequently invited to participate in a questionnaire study of gynecologic and obstetric history; 14 consented. Thus, our final study population included $14 \mathrm{CHH}$ women with 42 pregnancies.

\section{Methods}

All 14 patients were either interviewed by one of the authors (EH) for data regarding reproductive and obstetric history $(\mathrm{n}=10)$ or they provided the information using a specific questionnaire $(n=4)$. The interview and questionnaire covered pregnancy-related issues such as the number and outcome of pregnancies, pregnancy complications, pregnancy weeks (pw) at delivery, mode of delivery, delivery and post-partum complications and birth weight (BW), birth length (BL) and Apgar score of the newborns. Medical records of maternal outcomes were reviewed for all women, whereas offspring's medical records were obtained only with a separate permission given by 9 of the 14 women and involving 19 children.

BWs and BLs of the offspring were compared with the Finnish growth references [16] and transformed into Z-scores for all newborns. We excluded from further growth analysis a pair of twins and one child born prematurely at 25 pw with IUGR.

An ethical approval was obtained from the Research Ethics Committee of the Hospital District of Helsinki and Uusimaa (HUS/836/2018 Institutional Research Ethics Committee).

\section{Mutation analysis}

All RMRP mutations had been detected by Sanger sequencing either at Laboratory HUSLAB, Finland, or as a part of previous or ongoing research at Folkhälsan Institute of Genetics, Helsinki [17, 18].

\section{Results \\ Cohort characteristics}

The study cohort consisted of $14 \mathrm{CHH}$ women with 42 pregnancies (Table 1). At data collection, the median age of the cohort was 45.0 years (range 31-72 years). All patients had genetically confirmed $R M R P$ mutation NR_003051.3: n.71A $>\mathrm{G}$ in either homozygous $(\mathrm{n}=11)$ or compound heterozygous $(\mathrm{n}=3)$ state. The median height of the cohort was $124 \mathrm{~cm}$, range $105-139 \mathrm{~cm}$ $\left(4^{\prime} 1^{\prime \prime}\right.$, range $\left.3^{\prime} 5^{\prime \prime}-4^{\prime} 7^{\prime \prime}\right)$.

According to the clinical categorization of immunodeficiency in $\mathrm{CHH}, 6 / 14$ females had clinical symptoms of immunodeficiency in adulthood, mostly recurrent rhinosinusitis. Three of the six were classified as having 
Table 1 Type of 42 pregnancies in 14 women with $\mathrm{CHH}$

\begin{tabular}{llll}
\hline Type of pregnancy & $\begin{array}{l}\mathbf{N} \text { (\% of all } 42 \\
\text { pregnancies) }\end{array}$ & $\begin{array}{l}\text { Maternal } \\
\text { age } \\
\text { (median) }\end{array}$ & $\begin{array}{l}\text { Maternal } \\
\text { age } \\
\text { (range) }\end{array}$ \\
\hline Early miscarriage $\left(<12 \mathrm{pw}^{\mathrm{a}}\right)$ & $8(19)$ & $34^{\mathrm{b}}$ & $23-40^{\mathrm{b}}$ \\
$\begin{array}{l}\text { Late miscarriage }(<22 \mathrm{pw}) \\
\text { Ectopic pregnancy }\end{array}$ & $1(2)$ & & \\
$\begin{array}{l}\text { Induced abortion } \\
\begin{array}{l}\text { Term delivery }(37-42 \\
\text { pw) including one twin }\end{array}\end{array}$ & $5(12)$ & 34.5 & $34-35$ \\
$\quad 250)$ & $32^{\mathrm{c}}$ & $23-39$ \\
$\begin{array}{l}\text { delivery } \\
\text { Preterm delivery }(<37 \mathrm{pw})\end{array}$ & $1(2)$ & & \\
\hline
\end{tabular}

${ }^{a}$ pw, pregnancy weeks

b Combined data from all miscarriages

c Combined data from all pregnancies leading to delivery

clinical combined immunodeficiency because of opportunistic infections like severe herpes virus infections or recalcitrant warts [19].

\section{Miscarriages, ectopic pregnancies and induced abortions} Miscarriages $(n=9)$ were reported by 7 women. Eight miscarriages occurred during first trimester. None of the women had recurrent miscarriage, defined as loss of three or more consecutive pregnancies. Ectopic pregnancies occurred in two women. However, $89 \%(8 / 9)$ had also a successful pregnancy leading to a delivery.

Five induced abortions were reported in four women. Three were induced because of social indications and two because of fetal indications other than $\mathrm{CHH}$.

\section{Deliveries}

A total of 27 live births, including one pair of twins, were reported in 12 women. Maternal characteristics in pregnancies leading to delivery are presented in Table 2. Median maternal age at delivery was 32 years (range 24-45 years). Twenty-six (96\%) of the children were born at full-term (pw $37+0-41+6$ ). One preterm delivery due to fetal indication at pw 25 was reported.

All infants were delivered by CS. Two trials of vaginal labor, one induced and one spontaneous, were converted

Table 2 Maternal characteristics $(n=12)$ in 26 pregnancies leading to delivery

\begin{tabular}{|c|c|c|}
\hline Characteristics & Median & Range \\
\hline Age (years) & 32 & $24-45$ \\
\hline Height (cm / ft-inch) & $124 ; 4^{\prime} 11^{\prime}$ & $105-139 ; 3^{\prime} 5^{\prime \prime}-4^{\prime} 7^{\prime}$ \\
\hline BMI before pregnancy $\left(\mathrm{kg} / \mathrm{m}^{2}\right)^{\mathrm{a}}$ & 33.5 & $29.4-59$ \\
\hline Weight gain during pregnancy $(\mathrm{kg} ; \mathrm{lb})^{b}$ & $8.4 ; 18.5$ & $2.7-12.6 ; 5.6-27.8$ \\
\hline
\end{tabular}

\footnotetext{
${ }^{a}$ Data available from 21 pregnancies
}

${ }^{b}$ Data available from 16 pregnancies to CS, one of them complicated by chorioamnionitis. Indications for CS are presented in Table 3. Malpresentation was reported in six cases: fetus was either in breech or occiput posterior presentation in four and two cases, respectively. Two women had had two CSs, and three and two women had had three and four CSs, respectively. In four CSs, delivery of the baby was difficult and in two cases vacuum-extraction was required also in CS. Successful epidural anesthesia was difficult to accomplish potentially due to disproportionate spinal anatomy in $3 / 25$ women and they reported intraoperative pain.

\section{Maternal complications during pregnancy}

Ten of the 12 women with a history of delivery (83\%) reported one or several pregnancy-related complications (Table 4). Most of the complications were sporadic and did not require hospitalization. There was no severe maternal morbidity. Despite underlying immunodeficiency and increased susceptibility to infections, no infections requiring hospitalization during pregnancy were reported. Anemia was reported in four pregnancies (15\%) but none of them required blood transfusions or hospitalization. Two cases of placental insufficiency leading to fetal distress were diagnosed $(2 / 27,7 \%)$ based on elevated resistance or retrograde flow of $a$. umbilicalis and IUGR or fetal heart rate abnormalities and IUGR. No other placenta-related maternal complications, including severe pre-eclampsia or placental abruption, were reported.

\section{Offspring's birth characteristics}

Birth measurements were assessed in 19 offspring for nine women. We calculated Z-scores for $\mathrm{BL}$ and $\mathrm{BW}$ based on Finnish references for healthy children. We excluded a pair of twins and one child born prematurely

Table 3 Indication and type of cesarean section in 26 deliveries

\begin{tabular}{lll}
\hline Indication for CS $^{\text {a }}$ & N & Type of CS planned/emergency \\
\hline CPD $^{b, c}$ & 9 & (1 Emergency, 8 planned) \\
Previous CS & 9 & Planned \\
CPD and previous CS & 4 & Planned \\
Twin pregnancy and precious CS & 1 & Planned \\
Unsuccessful labor induction and & 1 & Emergency \\
IUGR & \\
IUGR and asphyxia & 1 & Emergency \\
Arrest of labor and fetal position & 1 & Emergency \\
\hline a CS cesarean section & & \\
b CPD cephalo-pelvic disproportion & \\
c In two cases vacuum extraction required \\
d IUGR intrauterine growth restriction
\end{tabular}


Table 4 Maternal disorders predominantly related to pregnancy in $\mathbf{2 6}$ pregnancies leading to delivery

\begin{tabular}{|c|c|c|}
\hline & $\mathrm{N}$ & $\begin{array}{l}\% \text { of } 26 \\
\text { pregnancies }\end{array}$ \\
\hline \multicolumn{3}{|l|}{ Maternal disorders related to pregnancy } \\
\hline Anemia $^{a}$ & 4 & 15 \\
\hline Hypertension $^{b}$ & 3 & 12 \\
\hline Gestational diabetes $^{c}$ & 3 & 12 \\
\hline Placental insufficiency & 2 & 8 \\
\hline Ischial pain & 1 & 4 \\
\hline Chorioamnionitis & 1 & 4 \\
\hline Subjective respiratory distress (3rd trimester) & 1 & 4 \\
\hline First-trimester bleeding & 1 & 4 \\
\hline Hyperemesis & 1 & 4 \\
\hline \multicolumn{3}{|l|}{ Post partum complications } \\
\hline Cesarean section wound infection & 1 & 4 \\
\hline Other post-partum infection & 2 & 8 \\
\hline
\end{tabular}

a Macrocytic anemia in 3 cases, iron deficiency 1 case; none required blood cell transfusions

${ }^{b}$ Blood pressure (BP) $>140 / 90 \mathrm{mmHg}$ or systolic BP increase $>30 \mathrm{mmHg}$ or diastolic $B P$ increase $>15 \mathrm{mmHg}$ during pregnancy

c Diet or insulin controlled

Table 5 Offspring's birth characteristics $(n=16)$

\begin{tabular}{lll}
\hline Characteristic & Median & Range \\
\hline Pregnancy week & $38+4$ & $37+2-41+3$ \\
Birth weight $(\mathrm{g}, \mathrm{lb})$ & $3010 ; 6.64$ & $2100-3320 ; 4.63-7.32$ \\
Birth weight Z-score & -0.6 & $-3.3-0.0$ \\
Birth length (cm, ft-inch) & $48 ; 1^{\prime} 7^{\prime \prime}$ & $45.5-50 ; 1^{\prime} 6^{\prime \prime}-1^{\prime} 8^{\prime \prime}$ \\
Birth length (Z-score) & -0.4 & $-2.4-+0.7$ \\
Apgar score (5 min) & 9 & $4-10$ \\
\hline
\end{tabular}

One pair of twins and one preterm baby were excluded from the analysis

(at $25 \mathrm{pw}$ ) from further analysis. In the remaining neonates $(n=16)$, both $B L$ and BW were in the majority below the normal mean (for BL median Z-score - 0.4, for BW median Z-score - 0.6) (Table 5). However, both measurements remained within the normal distribution (Z-score $>-2.0$ ), except for one newborn whose BL Z-score was -2.4 and BW Z-score -3.3.

\section{Discussion}

Pregnant women with skeletal dysplasia are at an increased risk of maternal and perinatal morbidity and mortality $[1,2,20]$. Recently, a multidisciplinary, international, consensus-based best practice guideline was provided as a minimum standard of care to minimize associated health risks, and to improve outcomes for pregnant women with skeletal dysplasia [21]. The guidelines concluded, that the increased risks of pregnancy in these situations are related to multiple factors such as cardiopulmonary and musculoskeletal factors in pregnant women. However, all skeletal dysplasias have their own specific features which may affect fertility and obstetric prognosis. Consequently, detailed data on pregnancies in different skeletal dysplasias is warranted.

Our study evaluated pregnancy outcomes in women with $\mathrm{CHH}$ from a unique Finnish cohort including 56 women with genetically confirmed $\mathrm{CHH}$. We were able to review a total of 42 pregnancies in 14 women, 26 of which led to delivery. Typical manifestations of $\mathrm{CHH}$, including severe short stature and immunodeficiency, may have negative impact on fertility and reproduction. However, gynecologic and obstetric problems in patients with $\mathrm{CHH}$ have received only scant attention. We have previously published reports on diversity of pubertal development and gynecologic health in $\mathrm{CHH}$ [11-13]. To the best of our knowledge, no comprehensive obstetric reports have ever been published, and the very limited data on pregnancies in $\mathrm{CHH}$ are based on single case reports $[14,15]$. This is thus the first study to evaluate reproductive and obstetric outcomes in a larger cohort of women with $\mathrm{CHH}$.

The miscarriage rate in our cohort was $21 \%$, which is not increased compared with rates in the general population (15-25\%) [22]. All but one miscarriage occurred during the first trimester. Moreover, 86\% (6/7) of women with one or two miscarriages, also had a successful pregnancy and delivery reflecting positive obstetric prognosis. Thus, $\mathrm{CHH}$ does not seem to predispose affected women to recurrent miscarriage.

The total number of induced abortions, $(12 \%, 5 / 42)$ did not differ from the data for the general population, as reported in the Finnish national pregnancy termination registry [23]. According to the national data, $93 \%$ of pregnancy terminations in Finland are performed because of social indications (unplanned pregnancies), compared to only $3.4 \%$ for fetal abnormality [23]. In our $\mathrm{CHH}$ population, a social indication was reported in $60 \%(3 / 5)$ of the terminations while $40 \%(2 / 5)$ were due to fetal indications. The number of unplanned, terminated pregnancies was thus not increased among the women with $\mathrm{CHH}$. However, the small number of induced abortions does no allow any solid conclusions.

Most of the pregnancies leading to a delivery were full-term. Preterm birth is defined as delivery under 37 completed weeks of gestation. In 2013, in the United States, $11.4 \%$ of all babies were born preterm [24]. In Finland in 2018, 5.8\% of babies were born under 37 gestational weeks [25]. In our cohort, $96 \%$ of babies were born fullterm, and there was only one early preterm birth (pw 25; 1/27 baby born, 3.7\%). We did not observe any increase in the rate of complications, such as pregnancyrelated hypertensive disorders or gestational diabetes, as 
compared with the general Finnish and Nordic population [26, 27]. Maternal BMI was increased before pregnancy and an average weight gain during pregnancy was $8.4 \mathrm{~kg}(18.5 \mathrm{lb})$. However, according to best-practice guidelines, BMI does not take into consideration body proportions in skeletal dysplasia, and there are no evidence-based recommendations concerning gestational weight gain. A reasonable approximation in short stature women with bone dysplasia is to recommend weight gain in the lowest range, a total of 5-9 kg (11-19.8 lb) over the course of pregnancy [21].

Since the growth of offspring is not generally affected in a recessively inherited disease, normal size of the fetus' head in a smaller maternal pelvis can cause CPD and result in dystocia. Moreover, breech presentation and malpresentations might be more common in women with short stature. In our study all subjects had a CS, and seven women had recurrent CSs. Recurrent CSs increase the risk for placental abruption, placentation disturbances and post-partum hemorrhage [27]. In our series such complications in women with recurrent CS were not reported. However, a vacuum extraction was required due to $\mathrm{CPD}$ and malpresentation twice even in planned CS, highlighting the importance of preparation for intrapartum complications.

The main limitation of this study is the retrospective study design. Number and type of pregnancies and diagnoses during pregnancies were confirmed from national registry. However, information about various subjective symptoms during pregnancy were mainly based on patient interviews and questionnaires. The reliance of self-reported data is subjected to recall bias. This study is by far the largest series reporting outcome of pregnancies in women with $\mathrm{CHH}$. However, as only 14 women altogether were included, the small sample size needs to be acknowledged as a limitation, unavoidable in rare diseases. Phenotypic differences in $\mathrm{CHH}$ are wide. Severely affected patients may not try to conceive, they may not conceive spontaneously, or they may not want to participate in the study, and among them obstetric prognosis might be poorer than in this study population. Although we did not systematically collect data on the use of assisted reproductive treatments from the patients, we are aware that these treatments have been used in some instances.

Fertility and reproduction are very important factors in young women's life. Decision about subjective willingness and capability of carrying a pregnancy should be based on patient's right to get all potential information preconceptionally. According to best-practice guidelines, preconceptional medical evaluation is recommended to all women with skeletal dysplasia, to consider factors that may impact safety of pregnancy, mode of delivery, and anesthetic management [21]. Due to rarity of skeletal dysplasias, pregnancies need to be assessed and managed in facilities that are aware of the potential complications, and have the skills and resources to anticipate and manage them effectively [21]. Anesthetic assessment should be carried out early in the third trimester because of challenges in anesthetic management and the risk of an emergency CS.

\section{Conclusions}

In conclusion, our study on pregnancies and deliveries in $\mathrm{CHH}$ shows encouraging results and indicates that women with $\mathrm{CHH}$, even with remarkable growth restriction, can successfully conceive and complete a normal pregnancy until term delivery. Despite underlying immunodeficiency and increased susceptibility to infections, no infections requiring hospitalization during pregnancy were reported. Because of potential fetal and maternal risks, pregnancies and deliveries in women with $\mathrm{CHH}$ warrant careful advance planning and preparing. Further studies, preferably in an international study setting, are needed to further elucidate pregnancy and delivery outcomes in $\mathrm{CHH}$ and other rare skeletal dysplasias.

\section{Abbreviations}

CHH: Cartilage-hair hypoplasia; CPD: Cephalo-pelvic disproportion; CS: Cesarean section; IUGR: Intrauterine growth restriction; HILMO: National Hospital Discharge Registry; pw: Pregnancy weeks; BW: Birth weight; BL: Birth length; BP: Blood pressure.

\section{Acknowledgements}

Not applicable.

\section{Authors' contributions}

$\mathrm{EH}, \mathrm{SV}$ and OM conceived the study and reviewed the literature. EH collected data from medical records and questionnaires and interviewed the patients and analysed the results. EH, SV and OM prepared the manuscript. All authors critically revised the manuscript and approved the final version.

\section{Funding}

This study was supported by the Sigrid Jusélius Foundation, the Novo Nordisk Foundation, the Folkhälsan Research Foundation, the Academy of Finland, the Foundation for Pediatric Research, the Helsinki University Research Funds, and the Swedish Childhood Cancer Foundation.

\section{Availability of data and materials}

Restrictions apply to the availability of data generated or analyzed during this study to preserve patient confidentiality. The corresponding author will on request detail the restrictions and any conditions under which access to some data may be provided.

\section{Ethics approval and consent to participate}

An ethical approval was obtained from the Research Ethics Committee of the Hospital District of Helsinki and Uusimaa (HUS/836/2018 Institutional Research Ethics (ommittee), and all study participants gave a written informed consent.

\section{Consent for publication}

Consents for publication were received from people participating in the study (written informed consent). Individual patients cannot be identified from the data shown. 


\section{Competing interests}

The authors declare that they have no competing interests.

\section{Author details}

${ }^{1}$ Department of Reproductive Medicine, Obstetrics and Gynecology, Helsinki University Hospital and University of Helsinki, P.O. Box 140 00029, Helsinki, Finland. ${ }^{2}$ Research Program for Clinical and Molecular Metabolism, University of Helsinki, Helsinki, Finland. ${ }^{3}$ Children's Hospital, University of Helsinki and Helsinki University Hospital, Helsinki, Finland. ${ }^{4}$ Folkhälsan Research Center, Helsinki, Finland. ${ }^{5}$ Department of Molecular Medicine and Surgery, Karolinska Institutet and Department of Clinical Genetics, Karolinska University Hospital, Stockholm, Sweden, Karolinska Institutet and Karolinska University Hospital, Stockholm, Sweden.

Received: 5 June 2020 Accepted: 10 November 2020

Published online: 19 November 2020

\section{References}

1. Sheiner E, Levy A, Katz M, Mazor M. Short stature: an independent risk factor for Cesarean delivery. Eur J Obst Gyn Rep Biol. 2005;120:175-8.

2. Hoover-Fong JE, Oswald G, Miller D, et al. Obstetrics and obstetrical anesthesia issues in women with dwarfism. Am J Obstet Gynecol. 2006;S185, abstract 608 .

3. Ruiter-Ligeti J, Czuzoj-Shulman N, Spence AR, Tulandi T, Abenhaim HA Pregnancy outcomes in women with osteogenesis imperfect: a retrospective cohort study. J Perinatol. 2016;36:828-31.

4. Pauli RM. Achondroplasia: a comprehensive clinical review. Orphanet J Rare Dis. 2019. https://doi.org/10.1186/s13023-018-0972-6.

5. Ayoubi JM, Jouk PS, Pons JC. Diastrophic dwarfism and pregnancy. Lancet. 2001;358:1778.

6. Melekoglu R, Celik E, Erasian S. Successful obstetric and anaesthetic management of a pregnant woman with achondroplasia. BMJ Case Rep. 2017. https://doi.org/10.1136/bcr-2017-221238.

7. Mäkitie O. Cartilage-hair hypoplasia in Finland: epidemiological and genetic aspects of 107 patients. J Med Genet. 1992;29:652-5.

8. Ridanpää M, van Eenennaam H, Pelin K, et al. Mutations in the RNA component of RNase MPR cause a pleiotropic human disease, cartilage-hair hypoplasia. Cell. 2001;104:195-203.

9. Mäkitie O, Kaitila I. Cartilage-hair hypoplasia: clinical manifestations in 108 Finnish patients. Eur J Pediatr. 1993;152:211-7.

10. Mäkitie O, Perheentupa J, Kaitila I. Growth in cartilage-hair hypoplasia. Pediatr Res. 1992;31:176-80.

11. Holopainen E, Vakkilainen S, Mäkitie O. Gynecologic health in cartilage-hair hypoplasia: a survey of 26 adult females. Am J Med Gen. 2019;179:190-5.

12. Holopainen E, Vakkilainen S, Mäkitie O. Gynecologic assessment of 19 adult females with cartilage-hair hypoplasia: high rate of HPV positivity. Orphanet J Rare Dis. 2018a. https://doi.org/10.1186/s13023-018-0945-9.

13. Holopainen E, Vakkilainen S, Mäkitie O. Diversity of pubertal development in cartilage-hair hypoplasia: two illustrative cases. J Ped Adolesc Gyn. 2018b:31:422-5.
14. Allanson JE, Hall JG. Obstetric and gynecologic problems in women with chondrodystrophies. Obst Gynecol. 1986;67:74-8.

15. Thavarajah $\mathrm{H}$, Berndl A. Pregnancy outcome in cartilage-hair hypoplasia, a rare form of dwarfism. Case Rep ObstetrGynecol. 2017. https://doi. org/10.1155/2017/4737818.

16. Pihkala J, Hakala T, Voutilainen P, Raivio K. Characteristic of recent growth curve (in Finnish). Duodecim. 1989;105:1540-6.

17. Ridanpää M, Sistonen P, Rockas S, Rimoin DL, Mäkitie O, Kaitila I. Worldwide mutation spectrum in cartilage-hair hypoplasia: ancient founder origin of the major $70 \mathrm{~A} \rightarrow \mathrm{G}$ mutation of the untranslated RMRP. Eur J Hum Gen. 2002;10:439-47.

18. Kostjukovits S, Degerman S, Pekkinen M, et al. Decreased telomere length in children with cartilage-hair hypoplasia. J Med Gen. 2017;54:365-70.

19. Vakkilainen S, Taskinen M, Klemetti P, Pukkala E, Mäkitie O. A 30-year prospective follow-up study reveals risk factors for early death in cartilagehair hypoplasia. Front Immunol. 2019. https://doi.org/10.3389/fimmu .2019.01581.

20. Boujenah J, Carbillon L, Banh P, Sibony O, Korb D. Term spontaneous trial of labor in nulliparous women of short stature: a hospitals-based cohort study. Eur J Obstetr Gynecol Rep Biol. 2020;246:181-6.

21. Savarirayan R, Rossiter JP, Hoover-Fong JE, et al. Best practice guidelines regarding prenatal evaluation and delivery of patients with skeletal dysplasia. Am J Obst Gynecol. 2018;219:545-62.

22. Larsen EC, Christiansen OB, Kolte AM, Macklon N. New insights into mechanisms behind miscarriage. BMC Med. 2013. https://doi. org/10.1186/1741-7015-11-154.

23. National Institute for Health and Welfare. Sexual and reproductive health, 2018. Available at https://www.thl.fi/en/web/thlfi-en/statistics/statistics -by-topic/sexual-and-reproductive-health. Accessed 13 May 2019

24. Frey HA, Klebanoff MA. The epidemiology, etiology, and cots of preterm birth. Semin Fetal Neonatal Med. 2016;21:68-73.

25. National Institute for Health and Welfare. Perinatal statistics-parturients, deliveries and newborns 2018.In Finnish at https://www.julkari.fi/bitst ream/handle/10024/138998/Tr49_19.pdf?sequence $=1 \&$ isAllowed=y. Accessed 19 Dec 2019

26. Skråstad RB, Hov G, Blaas HG, Romundstad PR, Salvesen KÅ. A prospective study of screening for hypertensive disorders of pregnancy at 11-13 weeks in a Scandinavian population. Acta Obstetr Gynecol Scand. 2014;93:1238-47.

27. Moeini R, Dalili H, Kavyani Z, et al. Maternal and neonatal outcomes of abnormal placentation: a case-control study. J Matern Fetal Neonatal Med. 2020; doi:https://doi.org/10.1080/14767058.2019.1678128. [Epub ahead of print]

\section{Publisher's Note}

Springer Nature remains neutral with regard to jurisdictional claims in published maps and institutional affiliations.

Ready to submit your research? Choose BMC and benefit from

- fast, convenient online submission

- thorough peer review by experienced researchers in your field

- rapid publication on acceptance

- support for research data, including large and complex data types

- gold Open Access which fosters wider collaboration and increased citations

- maximum visibility for your research: over 100M website views per year

At BMC, research is always in progress.

Learn more biomedcentral.com/submissions 